\title{
UV-Vis, IR and XPS analysis of UV induced changes in PVC composites
}

\author{
O. Birer ${ }^{\mathrm{a}}$, S. Suzer ${ }^{\mathrm{a}, *}$, U.A. Sevil ${ }^{\mathrm{b}}$, O. Guven ${ }^{\mathrm{b}}$ \\ ${ }^{a}$ Bilkent University, Chemistry Department, 06533 Ankara, Turkey \\ ${ }^{\mathrm{b}}$ Hacettepe University, Chemistry Department, 06531 Ankara, Turkey
}

\begin{abstract}
PVC undergoes a high degree of dehydrochlorination when exposed to energetic photons. The released $\mathrm{HCl}$ (acid), however, can be trapped if a suitable trapping material (base) is also enclosed within the solid matrix as a result of formation an acid-base adduct. Color changes or electrical conductivity changes can easily be obtained if suitable acid-base indicators or conducting polymers in their basic (nonconducting) form are enclosed in the matrix as trapping materials. We used bromcresol green and polyaniline for inducing color and electrical conductivity changes, respectively, within the PVC matrix as a result of exposure to UV light at $254 \mathrm{~nm}$. Both changes can to some extent be reversed by further exposure of the films to $\mathrm{NH}_{3}$ vapour. The color and electrical conductivity changes and their reversibility were followed by using UV-Vis, IR and XPS spectroscopic techniques. (C) 1999 Elsevier Science B.V. All rights reserved.
\end{abstract}

Keywords: Polyaniline; Poly(vinylchloride); Dehydrochlorination; Photochemistry

\section{Introduction}

PVC is one of the most widely used thermoplastics which undergoes a high degree of dehydrochlorination (loss of $\mathrm{HCl}$ ) when exposed to heat, energetic particles, $\gamma$-rays, electrons or UV light [1]. This limits its use for radiation processes and decreases the service time of outdoor materials [2]. The mechanism, various factors affecting the dehydrochlorination and especially the means to reduce it has been extensively investigated [3].

It is also possible to benefit from this dehydrochlorination by trapping the evolved $\mathrm{HCl}$ with a suitable

\footnotetext{
* Corresponding author. Tel.: 90312 2664946; fax: 90312 2664579.

E-mail address: suzer@ fen.bilkent.edu.tr (S. Suzer)
}

base incorporated within the matrix to induce electrical and/or optical changes. Recently Ogura et. al. converted PVC to an electrically conductive structure by casting it onto an electrochemically prepared polypyrrole film and later illuminating by UV light [4]. In our previous study we were able to prepare a polyaniline/polyvinylychloride (PVC/PANI) composite in its basic (nonconducting) form and converted it into its acidic (conducting) one by exposure to $\gamma$-rays or UV light [5]. In this contribution we report on the spectroscopic characterization of the changes responsible for the electrical conductivity increase in these PANI/ PVC composite films. The second part of our contribution concentrates on the spectroscopic characterization of the optical (color) changes upon UV exposure of the films of polyvinylchloride-bromcresol green (PVC/BG) composite films. 


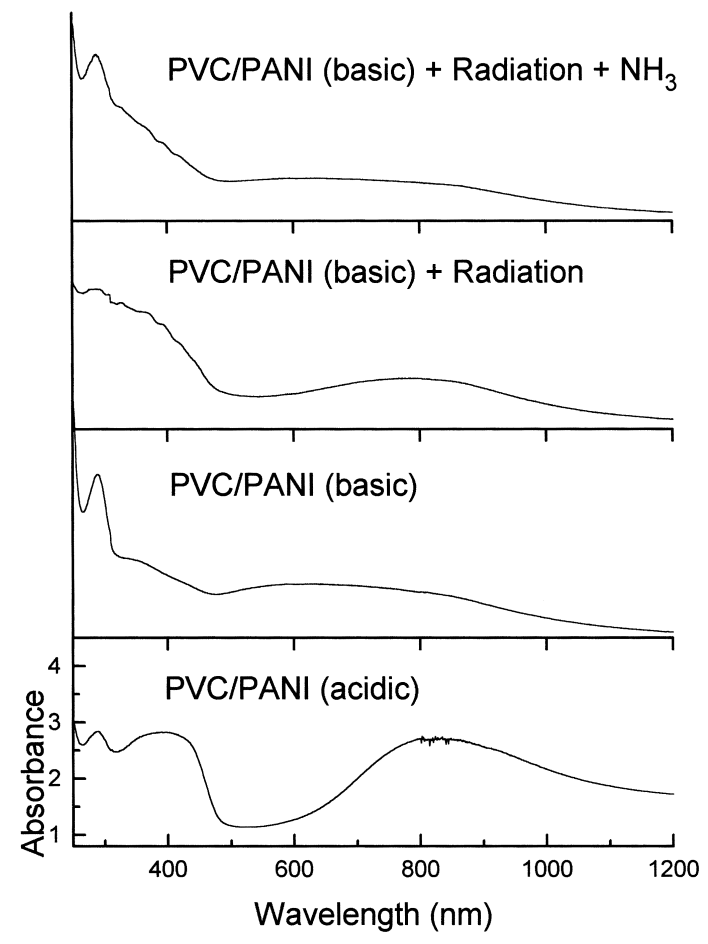

Fig. 1. Part of the UV-Vis-NIR spectra of PVC/PANI of ca. $15 \mu \mathrm{m}$ thick composite films in the acidic (conducting) form, basic (nonconducting) form before and after UV irradiation and after exposure to $\mathrm{NH}_{3}$ vapor.

\section{Experimental}

The PVC/PANI composites were prepared by dissolving aniline together with the commercially available polyvinylchloride in THF and cast into films by evaporation of the solvent. These films were later oxidised by $\left(\mathrm{NH}_{4}\right)_{2} \mathrm{~S}_{2} \mathrm{O}_{8}$ in acidic aqueous solutions according to the well established methods [6]. Reduction was achieved by treating films with aqueous solutions of $\mathrm{NH}_{4} \mathrm{OH}$ or $\mathrm{NaOH}$. The PVC/ $\mathrm{BG}$ blends were prepared by dissolving bromcresol green and PVC $(1: 10 \mathrm{w} / \mathrm{w})$ in THF and casting it on quartz windows. Both the PVC/PANI and PVC/ BG films were exposed to low pressure $\mathrm{Hg}$ light source (UVP R-52G model, $\lambda=254 \mathrm{~nm}, 4.9 \mathrm{eV}$ ) for varying duration.

FTIR and UV-Vis spectra were recorded with a Bomem MB102 and a Varian Cary 5E spectrometer respectively. A Kratos ES 300 electron spectrometer equipped with a $\mathrm{MgK} \alpha \mathrm{X}$-ray source at $1253.6 \mathrm{eV}$

\section{PVC/PANI(basic)+Radiation}
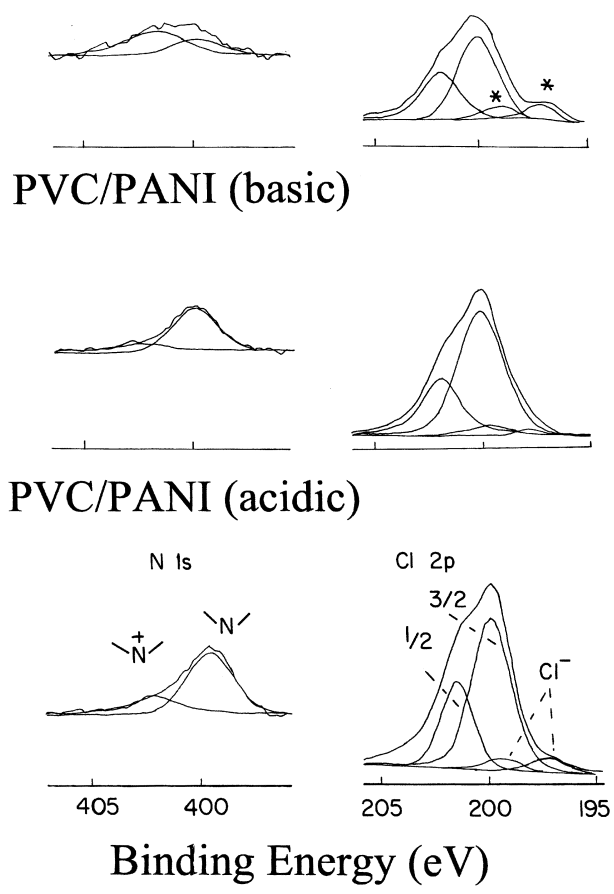

Fig. 2. N1s and Cl2p regions of the XPS spectra of of ca. $15 \mu \mathrm{m}$ thick composite films in the acidic (conducting) form, basic (nonconducting) form before and after UV irradiation.

was used to record XPS spectra. The chamber pressure was kept under $5 \times 10^{-9} \mathrm{~T}$ during experiments. The dosage of the X-rays were kept low $(12 \mathrm{kV}$, $5 \mathrm{~mA}$ ) to prevent radiation damages.

\section{Results and discussion}

\subsection{PVC/PANI films}

Electrical conductivity of PVC/PANI films prepared in the nonconducting form increased more than 3 orders of magnitude (from less than $10^{-6} \mathrm{~S} / \mathrm{cm}$ to ca. $10^{-3} \mathrm{~S} / \mathrm{cm}$ ) when exposed to ${ }^{60} \mathrm{Co} \gamma$-rays (200 kGy) or $254 \mathrm{~nm}$ UV radiation.

Fig. 1 displays the UV-Vis-NIR spectra of the films when prepared in acidic (conducting), basic (nonconducting) forms. The strong polaron band 


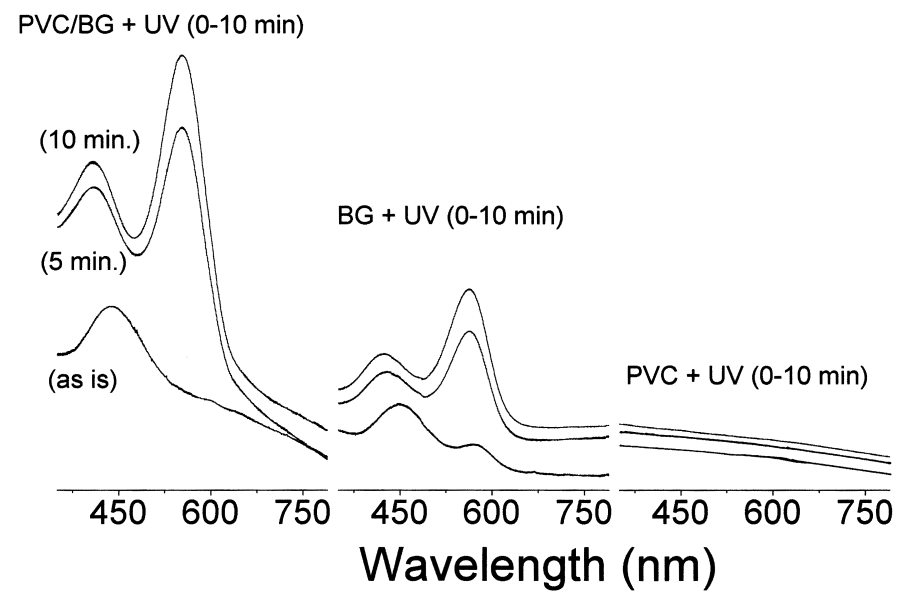

Fig. 3. Visible spectra of films of PVC, BG (bromcresol green) and PVC/BG before and after 5 and $10 \mathrm{~min}$. UV exposure.

starting around $600 \mathrm{~nm}$ in acidic form is the spectroscopic fingerprint of the electrical conductivity which is very weak and blue shifted in the basic form [7]. When these nonconducting (basic) films are exposed to UV radiation the polaron band starts to develop and red shifts which can be further reversed by exposure to $\mathrm{NH}_{3}$ vapors as shown in the figure.

In Fig. 2 part of the XPS spectra of the acidic and the basic films as well as the basic film after UV exposure are shown. Both the $\mathrm{N} 1 \mathrm{~s}$ and $\mathrm{Cl} 2 \mathrm{p}$ regions consists of multiplets. In the acidic film a relatively strong $-\mathrm{N}^{+}$-component is present. Similarly in the $\mathrm{Cl}$ $2 p$ region in addition to the organic $\mathrm{Cl}$ peaks assigned to $\mathrm{Cl}^{-}$are present [8]. These features confirm the presence of the charged species which are responsible for the electrical conductivity within the matrix. The intensity of both the $-\mathrm{N}^{+}$-and $\mathrm{Cl}^{-}$is very small in the basic films which increase after irradiation confirming again the radiation induced increase in the concentration of charge carriers, hence the electrical conductivity.

The FTIR spectra (not shown) also verify the increase in the electrical conductivity, as the free carrier absorption band starting around $1600 \mathrm{~cm}^{-1}$ develops upon irradiation. Further, carbonyl bands (1700-1800 $\mathrm{cm}^{-1}$ ) appear and spectral features around $1640-400 \mathrm{~cm}^{-1}$ change, which can be attributed to the increase in electrical conductivity because of irradiation.

From all these spectroscopic methods it can be clearly stated that the in-situ created $\mathrm{HCl}$ is captured by basic form of polyaniline in the matrix and the conductivity is increased as a result of the increased charge carrier concentration. As the PANI must be incorporated into the PVC matrix, it is difficult to obtain very high conductivities in the ranges $10^{2}-$ $10^{3} \mathrm{~S} / \mathrm{cm}$ which is typical for conducting polymers. Despite this fact, these may be used for on/off devices under irradiation environments, radiographic imaging/lithography or radiation monitoring.

\section{2. $P V C / B G$ films}

The Vis spectra of PVC only, BG only and PVC/ BG blend films are given in Fig. 3 in their unirradiated forms and after 5 and $10 \mathrm{~min}$ of irradiation. PVC has no absorbance in the visible region. BG has a faint yellow color and which itself is sensitive to UV. It slightly changes its color under UV exposure. However, PVC is totally unaffected from UV irradiation within the same exposure duration. The spectrum of the PVC/BG film is strongly affected by UV. The color change of the dye, as a result of the change in the $\mathrm{pH}$ of the matrix, seems to be catalysed within the PVC matrix. This can best be explained as the result of formation of an acid-base adduct between the radiatively created $\mathrm{HCl}$ and the dye as it is well established that dehydrochlorination is also acid catalysed [4]. The possibility of these composite films for radiation sensing or lithographic applications is promising. 


\section{Conclusions}

Our spectroscopic analysis confirm that the radiation induced dehydrochlorination of $\mathrm{PVC}$ is the reason for the induced electrical conductivity in the $\mathrm{PVC} /$ PANI and the optical change in the PVC/BG composite films. The process works not only with $\gamma$-radiation but with $254 \mathrm{~nm}$ UV light as well.

\section{Acknowledgements}

This work is partially supported by TUBITAK, the Scientific and Technical Research Council of Turkey, through the grant TBAG-COST/1 within the context of COST 518 Action supported by the European Community.

\section{References}

[1] W. Schnabel, Polymer Degradation, Macmillan, New York, 1985.

[2] E. Adem, M. Avalos-Borja, L. Cota, G. Burilla, Radiat. Phys. Chem. 39 (1992) 397.

[3] D. Braun, E. Bezdadea, Theory of Degradation and Stabilization, in Encyclopedia of PVC, 2rd ed., Marcel Dekker Inc., New York, 1989.

[4] K. Ogura, K. Kisaka, H. Frukawa, J. Polym. Sci. Part A: Polym. Chem. 33 (1996) 1375.

[5] U.A. Sevil, O. Guven, S. Suzer, J. Phys. Chem. B. 102 (1998) 3902.

[6] J.C. Chiang, A.G. MacDiarmid, Synth. Met. 13 (1986) 193.

[7] J.L. Bredas, G.B. Street, Acc. Chem. Res. 18 (1985) 309.

[8] P. Fluger, G.B. Street, J. Chem. Phys. 80 (1984) 544. 